\title{
Reverse Transcriptase Adds Nontemplated Nucleotides to cDNAs During 5'-RACE and Primer Extension
}

BioTechniques 30:574-582 (March 2001)

\author{
Dayue Chen and John T. \\ Patton \\ National Institutes of Allergy \\ and Infectious Diseases, \\ National Institutes of Health, \\ Bethesda, MD, USA
}

\section{ABSTRACT}

In determining the terminal sequences of the genomic dsRNAs of rotavirus by $5^{\prime}$-rapid amplification of cDNA ends (5'-RACE), it was found that most of the viral cDNAs contained extra nucleotides at their $5^{\prime}$ termini that had not been reported before on any rotavirus sequence. Although the extra nucleotides could be $d A, d C, d G$, or $d T$ residues, the extra nucleotides on the $c D N A s$ usually consisted of a single dT residue. Experiments performed with DNA/RNA duplexes indicated that reverse transcriptase has an associated terminal nucleotidyl transferase (TdT)-like activity, which can add nontemplated nucleotides to the $3^{\prime}$ ends of DNA, and that reverse transcriptase was responsible for the presence of the extra nucleotides detected on the 5'-RACE cDNAs. The TdT-like activity of reverse transcription was specific for double-stranded substrates (i.e., DNA/DNA or DNA/RNA duplexes) and was active over a wide range of temperatures and enzyme concentrations. Both com mercially available Moloney murine leukemia virus and avian myeloblastosis virus reverse transcriptases contained the TdT-like activity. This work implies that $5^{\prime}$ RACE and primer extension assays must be used carefully in determining the terminal sequences of nucleic acids because, under standard reaction conditions, reverse transcriptase can add nontemplated nucleotides to the 3' ends of cDNAs following templatedirected synthesis.

\section{INTRODUCTION}

Both rapid amplification of cDNA ends (RACE) and primer extension assays use reverse transcriptase to catalyze the template-directed synthesis of a cDNA. The RACE procedure is frequently used to generate full-length cDNA clones and to determine the precise terminal sequences of cellular and viral RNAs (5-7). In the initial step of RACE, a cDNA is produced by incubating an RNA with reverse transcriptase and one of two types of primers, either oligo-dT ( $3^{\prime}$-RACE) or a specific deoxyoligonucleotide that anneals closely to the $5^{\prime}$ end of the RNA (5'RACE). In the case of 5'-RACE, a homopolymer tail is then added to the end of the cDNA product with terminal deoxynucleotidyl transferase (TdT). Afterwards, the cDNAs are amplified by PCR using a gene-specific primer and an oligonucleotide complementary to the homopolymer tail. The amplified cDNAs can be sequenced directly or cloned into a plasmid for further characterization. In a typical primer extension assay, a primer anneals to the RNA of interest through specific base pairing and is extended by reverse transcriptase until the growing chain of cDNA reaches the $5^{\prime}$ end of the RNA template. The technique has long been used to measure the level of gene expression and to map the $5^{\prime}$ end of RNAs $(8,9)$.

In this study, we report that com mercially purchased Moloney murine leukemia virus (MMLV) and avian myeloblastosis virus (AMV) reverse transcriptases contain a TdT-like activity that can add one or more nontemplated nucleotides to the $3^{\prime}$ end of cDNAs upon the completion of template-directed synthesis. Under typical reaction conditions, the termini of $70 \%-80 \%$ of $5^{\prime}$-RACE cDNAs prepared with MMLV reverse transcriptase contained one or more nontemplated nucleotides. The TdT-like activity preferentially adds $\mathrm{A}$ residues to cDNAs and uses DNA/RNA or DNA/DNA duplexes as substrates. Because of this activity, strict reliance on $5^{\prime}$-RACE and primer extension to define the $5^{\prime}$-terminal sequence of RNA can yield misleading results.

\section{MATERIALS AND METHODS}

Cloning and Sequencing of $5^{\prime}$-RACE Products

dsRNA was purified from rotavirus SA11-4F (2), heated to $100^{\circ} \mathrm{C}$ for 2 min, and used as a template for making gene 8 cDNAs. The primer for cDNA synthesis, 5'-ATTAGAGACGTTTGCTTGCGTCAC-3', was complementary to nucleotides $322-345$ of the gene 8 (+)RNA. Reaction mixtures $(50 \mu \mathrm{L})$ contained $20 \mathrm{mM}$ Tris- $\mathrm{HCl}(\mathrm{pH} 8.4), 50$ $\mathrm{mM} \mathrm{KCl}, 2.5 \mathrm{mM} \mathrm{MgCl} 2,10 \mathrm{mM}$ dithiothreitol, $400 \mu \mathrm{M}$ each of the dNTPs, $0.5 \mu \mathrm{g}$ dsRNA, $100 \mathrm{nM}$ primer, and 200 U MMLV reverse transcriptase (SUPERSCRIPT II ${ }^{\mathrm{TM}}$; Life Technologies, Rockville, MD, USA) and were incubated at $45^{\circ} \mathrm{C}$ for $50 \mathrm{~min}$. The cDNA products were purified with GlassMax ${ }^{\circledR}$ spin cartridges (Life Technologies) and tailed by incubating them with $10 \mathrm{U}$ TdT (Life Technologies) and $200 \mu \mathrm{M}$ dGTP, $\mathrm{dATP}$, or dCTP in a volume of $25 \mu \mathrm{L}$ for $10 \mathrm{~min}$ at $37^{\circ} \mathrm{C}$. The tailed cDNAs were amplified by 30 cycles $\left(94^{\circ} \mathrm{C}\right.$ for $60 \mathrm{~s}$, $50^{\circ} \mathrm{C}$ for $45 \mathrm{~s}, 72^{\circ} \mathrm{C}$ for $90 \mathrm{~s}$ ) of PCR using an anchor primer and the gene 8 primer, 5'-aatggatccAGAGCTTCATA 
TCAACATAGCC-3', which contained a sequence complementary to nucleotides 285-308 of the gene 8 (+)RNA (uppercase) and a BamHI site (underlined). The oligonucleotides 5'ccggaattccecececececceccc- $3^{\prime}$ (EcoRI site underlined), 5'-ggccacgcgtcgactagtacgggiigggiigggiig- $3^{\prime}$ (SalI site underlined, $I=$ inosine $)$, and $5^{\prime}$-cggctcgagttttttttttttttttttt-3' (XhoI site underlined) were the anchor primers for dG-, dC-, and dA-tailed cDNAs, respectively. After purification, the PCR products were digested with BamHI and EcoRI (dGtailed cDNA), BamHI and XhoI (dAtailed cDNA), or BamHI and SalI (dCtailed cDNA), and were ligated into the BamHI/EcoRI sites (dG-tailed cDNA) or BamHI/SalI sites (dA- and dC-tailed cDNAs) of pUC19. Clones containing cDNA inserts were sequenced with a T7 Sequenase ${ }^{\circledR}$ version 2.0 DNA Sequencing kit (Amersham Pharmacia Biotech, Piscataway, NJ, USA) using a gene 8 primer that annealed to a region $60 \mathrm{nu}-$ cleotides downstream of the $5^{\prime}$ end of the gene $8(+)$ RNA.

\section{Preparation of T7 Run-Off Transcripts}

Gene $8(+)$ RNAs were made by runoff transcription of SP65 g8R with T7 RNA polymerase (13). Unincorporated nucleotides were removed by passing RNA samples through Micro-Select ${ }^{\circledR}$ D, G-50 spin columns (Eppendorf-5 Prime, Westbury, NY, USA). The quality of the RNA transcripts was evaluated by electrophoresis on $1 \%$ formaldehyde agarose gels (14).

\section{Preparation of DNA/RNA Duplexes}

Gel-purified oligonucleotides were used to prepare DNA/RNA duplexes. Oligonucleotide I, 5'-GGCGACTGA GACGCTTTA-3', is complementary to residues $7-24$ of the gene $8(+)$ RNA and forms a DNA/RNA duplex that leaves a 5'-RNA overhang of six nucleotides (Figure 1B, duplex I). Oligonucleotide II, 5'-GGCGACTGA GACGCTTTAAAAGCC-3', is complementary to the first 24 residues of the

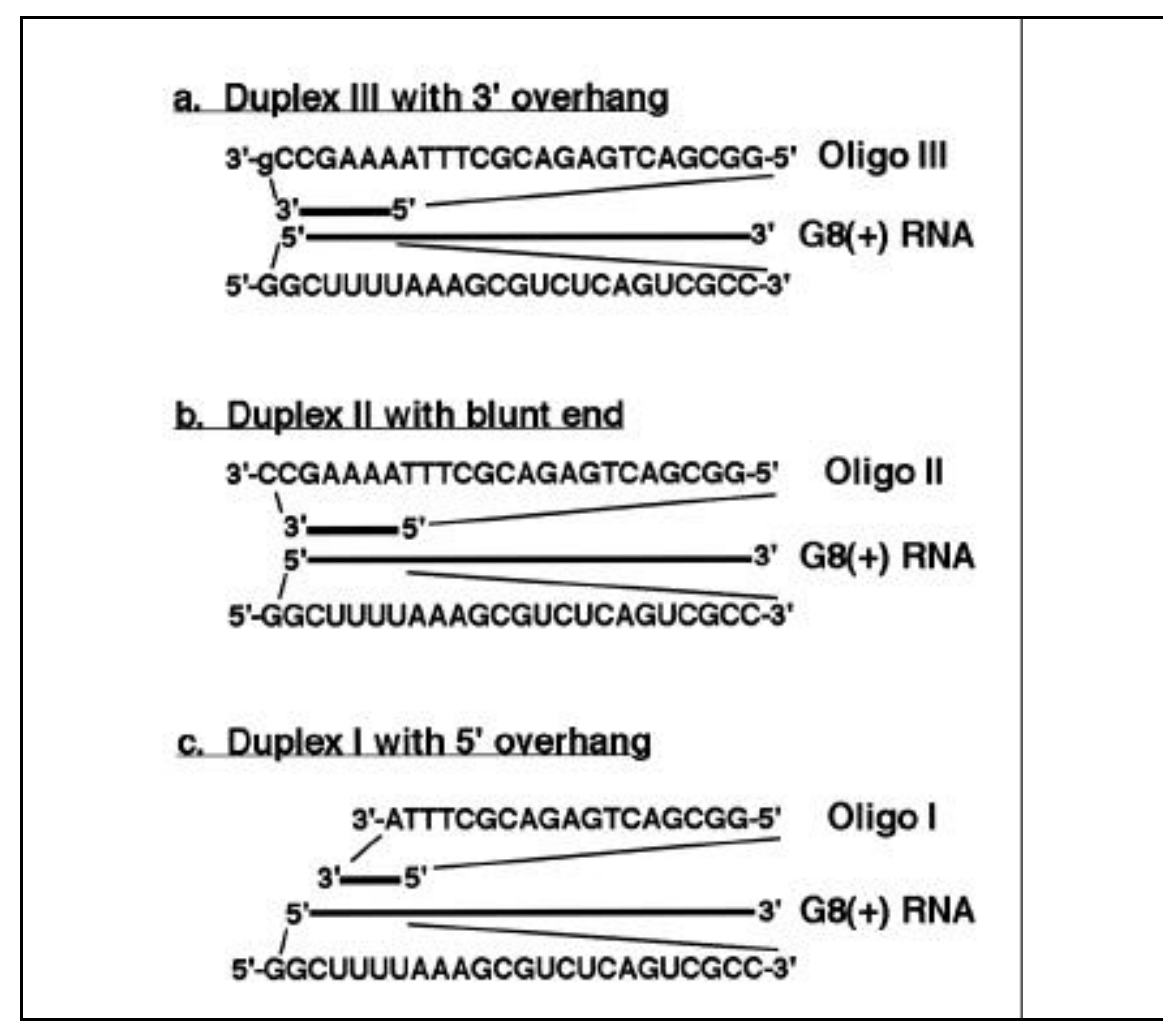

Figure 1. DNA/RNA duplexes I, II, and III. Terminal structure of DNA/RNA duplexes formed by annealing oligonucleotides I, II, and III to gene $8(+)$ RNA made by T7 transcription. Sequences of the oligonucleotides are given as well as the relevant sequences of the RNA. The nonviral nucleotide of oligonucleotide III is shown in lowercase.

gene 8 RNA and forms a DNA/RNA duplex in which the $5^{\prime}$ end of the RNA is blunt-ended with the $3^{\prime}$ end of the oligonucleotide (Figure 1B, duplex II). Oligonucleotide III, 5'-GGCGACTGA GACGCTTTAAAAGCCg-3' (lowercase is nonviral), is also complementary to the first 24 nucleotides of the gene 8 RNA but forms a DNA/RNA duplex with a $3^{\prime}$-DNA overhang of a single nucleotide (Figure 1B, duplex III). The oligonucleotides were $5^{\prime}$-end-labeled in a reaction mixture $(20 \mu \mathrm{L})$ containing $60 \mathrm{mM}$ Tris- $\mathrm{HCl}$ (pH 7.8), $10 \mathrm{mM}$ $\mathrm{MgCl}_{2}, 200 \mathrm{mM} \mathrm{KCl}, 50 \mu \mathrm{Ci}\left[\gamma_{-}{ }^{32} \mathrm{P}\right]$ ATP $\left(3000 \mathrm{Ci} / \mathrm{mmol}^{\text {; }} \mathrm{NEN}^{\circledR}\right.$ Life Science Products, Boston, MA, USA), 50 pmol oligonucleotide, and $4 \mathrm{U}$ T4 polynucleotide kinase (Life Technologies). After incubation for $30 \mathrm{~min}$ at $37^{\circ} \mathrm{C}$, ${ }^{32} \mathrm{P}$-labeled oligonucleotides were recovered by phenol-chloroformisoamyl alcohol extraction and ethanol precipitation and passed twice through Sephadex G-25. To prepare the DNA/ RNA duplexes, 5 pmol ${ }^{32} \mathrm{P}$-labeled or unlabeled oligonucleotides and $10 \mathrm{pmol}$ gene $8(+)$ RNA in $50 \mathrm{mM}$ Tris- $\mathrm{HCl}(\mathrm{pH}$ 8.3), $3 \mathrm{mM} \mathrm{MgCl}_{2}$, and $55 \mathrm{mM} \mathrm{KCl}$ were heated to $100^{\circ} \mathrm{C}$ for $2 \mathrm{~min}$ and annealed by incubating overnight at $42^{\circ} \mathrm{C}$.

\section{Assay for the Addition of Non- templated Nucleotides by Reverse Transcriptase to DNA/RNA Duplexes}

Reaction mixtures $(25 \mu \mathrm{L})$ contained 0.5 pmol 32P-labeled DNA/RNA duplex, either $500 \mu \mathrm{M}$ each dNTP or 500 $\mu \mathrm{M}$ one dNTP, $200 \mathrm{U}$ MMLV reverse transcriptase or $5 \mathrm{U}$ AMV reverse transcriptase, and the buffer provided by the supplier of the reverse transcriptase (Life Technologies) and were incubated for 60 min at $45^{\circ} \mathrm{C}$, unless otherwise indicated. After extraction with phenol-chloroform-isoamyl alcohol and precipitation with ethanol, the sizes of 32P-labeled oligonucleotides in the mixtures were analyzed by electrophoresis on $20 \%$ polyacrylamide sequencing gels containing $7 \mathrm{M}$ urea and autoradiography.

\section{RESULTS}

Sequence Analysis of Gene 8 cDNA Clones Generated by 5'-RACE

To determine the $5^{\prime}$-terminal se- 
quence of the gene $8(+)$ RNA of rotavirus SA11-4F by 5'-RACE (4), cDNAs were prepared from virion-derived gene 8 dsRNA using MMLV reverse transcriptase. The cDNAs were tailed with dATP, dCTP, or dGTP, am plified by PCR, and cloned into pUC19. Of 29 dATP-tailed clones, sequence analysis showed that $22(75.9 \%)$ had the $5^{\prime}$-terminal sequence, $5^{\prime}$-GGCTTTT-3' (Figure 2A). Based on earlier work $(1,12)$, this is the expected sequence for the $5^{\prime}$ end of the gene 8 RNA. However, seven clones $(24.1 \%)$ contained either one (G or C) or two (GT, GC, or CT) extra nucleotides upstream of the expected 5 -terminal sequence (Figure 2A). Of 34 dCTP-tailed clones, the $5^{\prime}$-terminal sequence of only 10 (24.9\%) agreed with expected gene 8 sequence (Figure 2B). For these 10 clones, the origin of the first two nucleotides GG in the 5'-terminal sequence $\left(5^{\prime}\right.$-GGCTTTT-3') is masked because of dCTP-tailing of the first-strand cDNA. Of the remaining 24 dCTP-tailed clones, $18(52.9 \%)$ contained an extra T, and $6(17.6 \%)$ contained an extra $\mathrm{C}$ upstream of the expected 5 'terminal sequence (Figure 2B). Similar to the dCTP-tailed clones, the majority (19 of 22 clones, $84.6 \%$ ) of the dGTP-tailed clones contained one or two extra nucleotides at their $5^{\prime}$ ends (Figure 2C). Of the 19 clones, 17 $(77.3 \%)$ contained an extra $\mathrm{T}$, one contained an extra GT, and one contained an extra TT. These results showed that the $5^{\prime}$-terminal sequences of the gene 8 cDNA clones produced by 5'-RACE were heterogeneous and that, in total, the majority of the clones contained one or more additional nucleotides upstream of the expected 5'-terminal sequence. The extra nucleotides were detected more often with cDNAs tailed with dCTP or dGTP than those tailed with dATP. For cDNAs tailed with dCTP or dGTP, the extra nucleotides upstream of the expected $5^{\prime}$-terminal gene 8 sequence were usually $\mathrm{T}$ residues.

When gene $8(+)$ RNA made by T7 transcription was used as the template for 5'-RACE, instead of virion-derived RNA, the $5^{\prime}$ ends of the gene 8 cDNA clones contained extra nucleotides in frequencies similar to those observed above (data not shown). Thus, even when the RNA used for 5'-RACE were made by transcribing a gene $8 \mathrm{cDNA}$ beginning with the sequence $5^{\prime}$ GGCTTTT-3', analysis of the clones indicated that the $5^{\prime}$ end of the RNA was heterogeneous in sequence and contained extra nucleotides upstream of the expected $5^{\prime}$-terminal sequence.

\section{Addition of Nontemplated Nucleotides to DNA/RNA Duplexes by Reverse Transcriptase}

Previous reports have indicated that the reverse transcriptases of AMV, MMLV, and HIV have an associated TdT-like activity $(3,10,11,15)$. To test whether or not this activity was responsible for the presence of the extra nucleotides, oligonucleotides I (18 nucleotides), II (24 nucleotides), and III (25 nucleotides) were 5 '-end-labeled with $32 \mathrm{P}$ and then annealed to gene 8 (+)RNAs, yielding DNA/RNA duplexes that contained a $5^{\prime}$-RNA overhang (I), a blunt-end (II), and a single-base 3'-DNA overhang (III), respectively (Figure 1). The terminal structure of duplex II mimics the blunt-end generated by reverse transcriptase during firststrand synthesis on an RNA template. The three DNA/RNA duplexes were

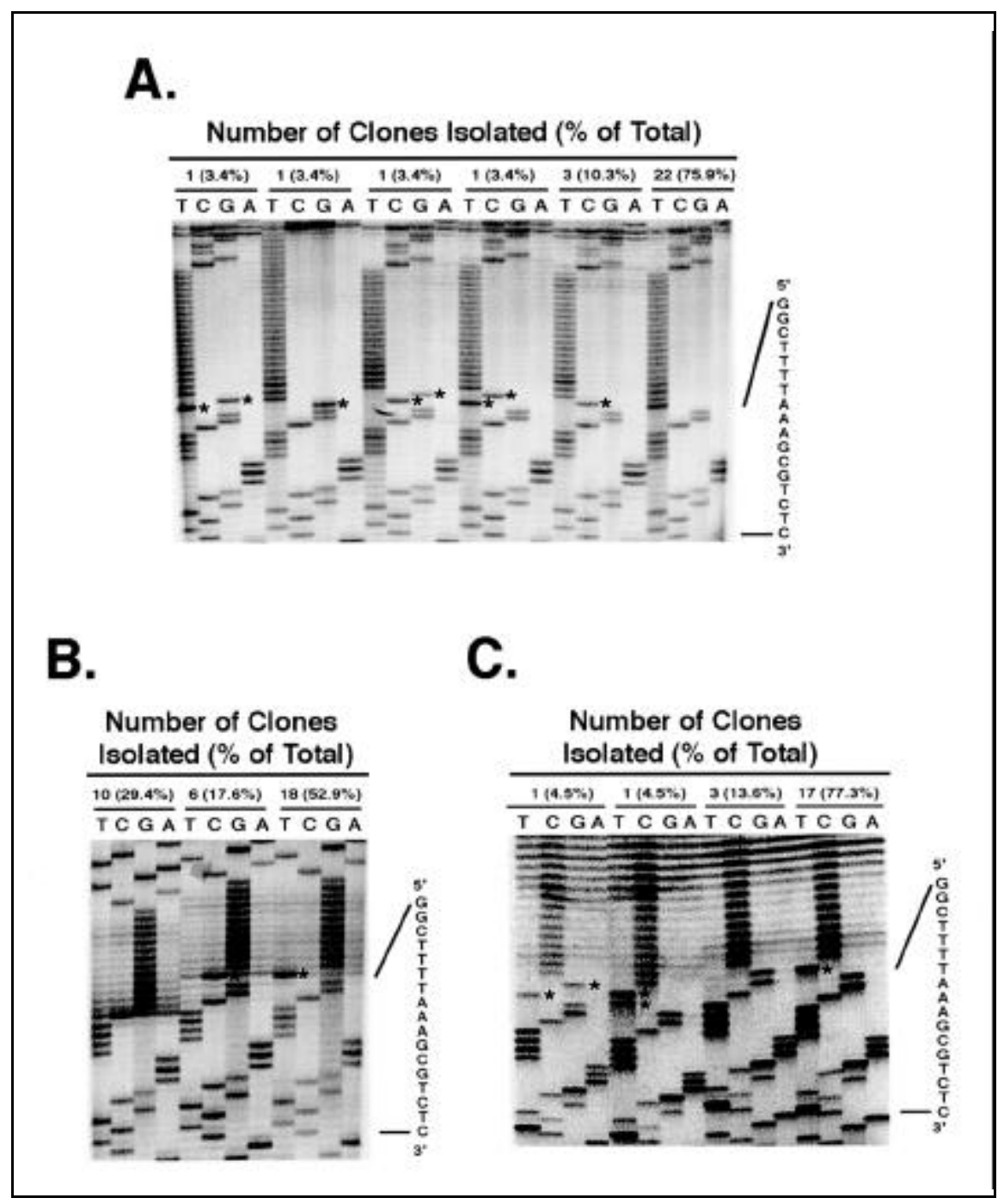

Figure 2. Sequence analysis of gene $85^{\prime}$-RACE clones. $5^{\prime}$-RACE was used to prepare cDNAs of the $5^{\prime}$ end of rotavirus gene $8(+)$ RNAs. The cDNAs were tailed with dATP (A), dCTP (B), or dGTP (C), am plified by PCR, and ligated into pUC19. Dideoxynucleotide sequencing was used to analyze the junction region between the homopolymer tail and the $5^{\prime}$ end of the gene 8 -specific sequence of these clones. Unexpected nucleotides found upstream of the gene 8-specific sequence are indicated with asterisks. The $5^{\prime}$-terminal sequence of the gene $8(+)$ RNA is shown. 
incubated with MMLV or AMV reverse transcriptase, at concentrations suggested by the supplier, in the presence of all four dNTPs or one individual dNTP. The sizes of the 32P-labeled oligonucleotides of the DNA/RNA duplexes were evaluated by electrophoresis (Figure 3A). When DNA/RNA duplex II was incubated with all four dNTPs and MMLV or AMV reverse transcriptase, $90 \%$ and $30 \%$, respectively, of the oligonucleotides recovered from the reaction mixtures had increased in size by one or more nucleotides (lanes 3 and 11). When the four dNTPs were incubated individually with MMLV and AMV reverse transcriptase, in all cases the products included oligonucleotides that had increased in size by at least one nucleotide (lanes 4-7 and 12-15). How ever, the efficiency with which the nontemplated nucleotides were added to the oligonucleotides varied depending on which dNTP was present (lanes 4-7 and 12-15) and was calculated to follow the order $\mathrm{A}>\mathrm{G} \geq \mathrm{C}>\mathrm{T}$. The addition of two or more nontemplated nucleotides to oligonucleotides occurred much less frequently than did the addition of a single nucleotide, and the addition of two or more nontemplated nucleotides was most efficient in reaction mixtures that contained both dATP and MMLV reverse transcriptase. Because oligonucleotides that contained a single nontemplated nucleotide (i.e., the 25nucleotide products) exhibited slight differences in electrophoretic mobility depending on which nucleotide was added (lanes 4-7 and 12-15), it was possible to conclude that in the presence of all four dNTPs, dATP was added to oligonucleotides more efficiently than the other three dNTPs (lanes 3 vs. 5 and lanes 11 vs. 13).

Due to the six nucleotide $5^{\prime}$-RNA overhang, incubation of DNA/RNA du- plex I with reverse transcriptase is expected to extend the oligonucleotide from 18 to 24 nucleotides via templatedependent cDNA synthesis (Figure 1). If reverse transcriptase transfers nucleotides to the cDNA in a nontemplatedependent manner upon the completion of template-dependent synthesis, then the length of the oligonucleotide will exceed 24 nucleotides. Indeed, such experiments revealed that greater than $90 \%$ of the total extended oligonucleotides recovered from reaction mixtures containing MMLV reverse transcriptase were 25 nucleotides or more in size (Figure 3A, lanes 8 and 9). In contrast, when AMV reverse transcriptase was used, approximately $25 \%$ of the total extended oligonucleotides were 25 nucleotides in length (lanes 16 and 17). The results obtained with DNA/RNA duplexes I and II indicate that both these commercially purchased reverse transcriptases have TdT-like 
activity, which adds nontemplated nucleotides to the 3 -end of cDNAs. Unlike duplexes I and II, MMLV and AMV reverse transcriptase did not add nontemplated nucleotides to oligonucleotides I and II (Figure 3B). Thus, the substrate for the TdT-like activity of reverse transcriptase does not include ssDNA. In related experiments, it was shown that the TdT-like activity of reverse transcriptase could add nontem plated nucleotides to blunt-ended DNA/DNA duplexes but could not add nucleotides to ssRNA (data not shown).

The addition of the first nontemplated nucleotide to the oligonucleotides of duplexes I (5'-RNA overhang) and II (blunt-end) occurred more frequently in reaction mixtures containing reverse transcriptase and all four dNTPs than did the addition of the second or third nontemplated nucleotide (Figure 3A). This suggested that the transfer of one nontemplated nucleotide produced $3^{\prime}$ overhangs on these duplexes, which then made them poorer substrates for the TdT-like activity of reverse transcriptase. To test this, we compared the ability of MMLV and AMV reverse transcriptase to transfer nontemplated nucleotides to DNA/RNA duplexes that contained a 5'-RNA overhang (I), a blunt-end (II), and a single-base 3 'DNA overhang (III). The results showed that MMLV and AMV reverse transcriptase added nontemplated nucleotides to $91 \%$ and $25 \%$, respectively, of the extended oligonucleotides of duplex I (Figure 4, lanes 5 and 8), to $87 \%$ and $26 \%$ of the oligonucleotides of duplex II (lanes 6 and 9), but to only $27 \%$ and $0 \%$ of the oligonucleotides of duplex III (lanes 7-10). The decreased frequency of the transfer of nontem plated nucleotides to the oligonucleotides of DNA/RNA duplex III relative to those of duplexes I and II showed that the TdT-like activity of reverse transcriptase adds nucleotides to blunt-ended substrates more efficiently than to substrates with $3^{\prime}$ overhangs.

\section{Effect of Reverse Transcriptase Concentration and Temperature on the Addition of Nontemplated Nucleotides}

To evaluate the effect of reverse transcriptase concentration on the addition of nontemplated nucleotides,

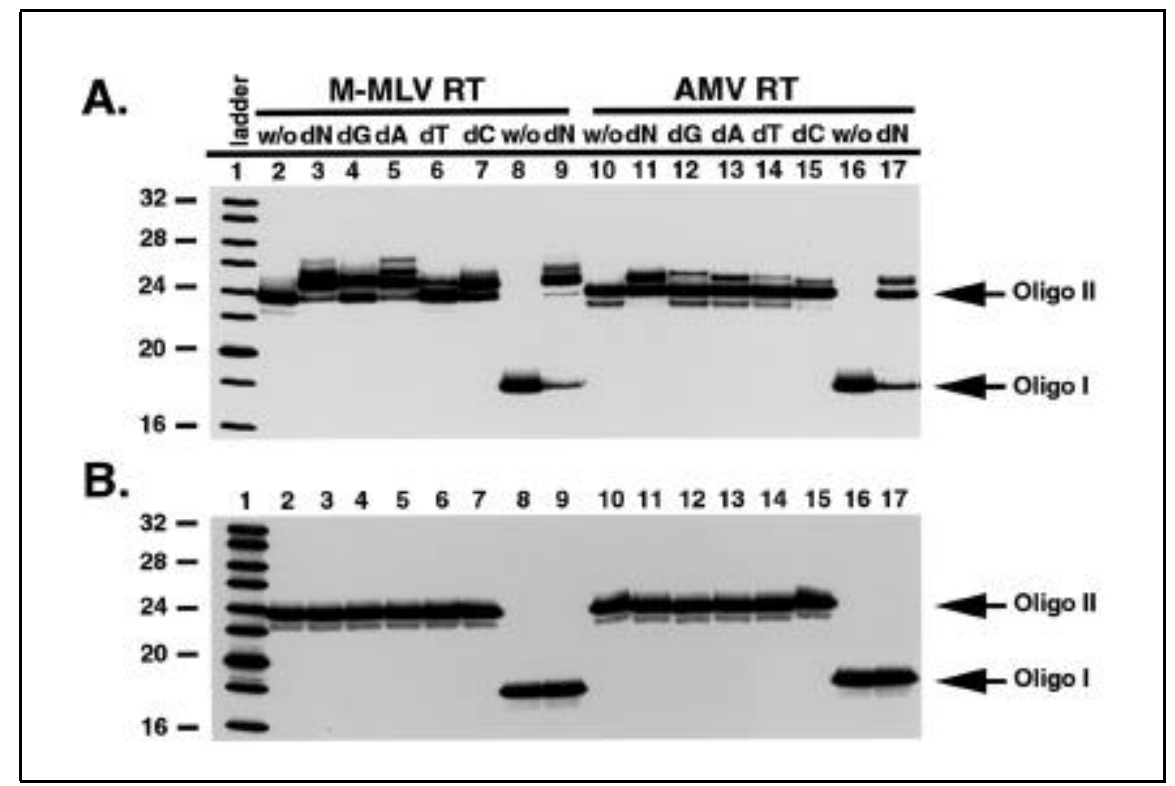

Figure 3. Addition of nontemplated nucleotides to DNA/RNA duplexes. (A) ${ }^{32} \mathrm{P}$-labeled DNA/RNA duplexes I (5'-RNA overhang; lanes 8, 9, 16, and 17) and II (blunt-end; lanes 2-7 and 1-15) and (B) 32Plabeled oligonucleotides I (lanes 8, 9, 16, and 17) and II (lanes 2-7 and 10-15) were incubated with MMLV or AMV reverse transcriptase and all four dNTPs $(\mathrm{dN})$ or one of the four dNTPs (dG, dA, dT, and $\mathrm{dC}$ ), or in the absence of dNTPs (w/o). The sizes of oligonucleotides recovered from reaction mixtures were determined by electrophoresis and autoradiography. End-labeled oligonucleotides were used as size markers (lane 1). The positions of end-labeled oligonucleotides used in the assays are indicated with arrows: Oligo I (18 nucleotides) and Oligo II (24 nucleotides).
DNA/RNA duplex I (5'-RNA overhang) was incubated with serial dilutions of MMLV and AMV reverse transcriptase. Analysis of the extended oligonucleotides (i.e., those $\geq 24$ nucleotides) from the assays showed that the TdT-like activity decreased by eightfold as the amount of MMLV reverse transcriptase was reduced from 100 to $12.5 \mathrm{U}$ (Figure 5A, lanes 6-9). Further reduction in the amount of MMLV reverse transcriptase had little effect on TdT-like activity (lanes 10-12). In contrast, dilution of AMV reverse transcriptase had no impact on its TdT-like activity (lanes 13-15). Higher concentrations of AMV reverse transcriptase were not available for testing. These results indicate that reverse

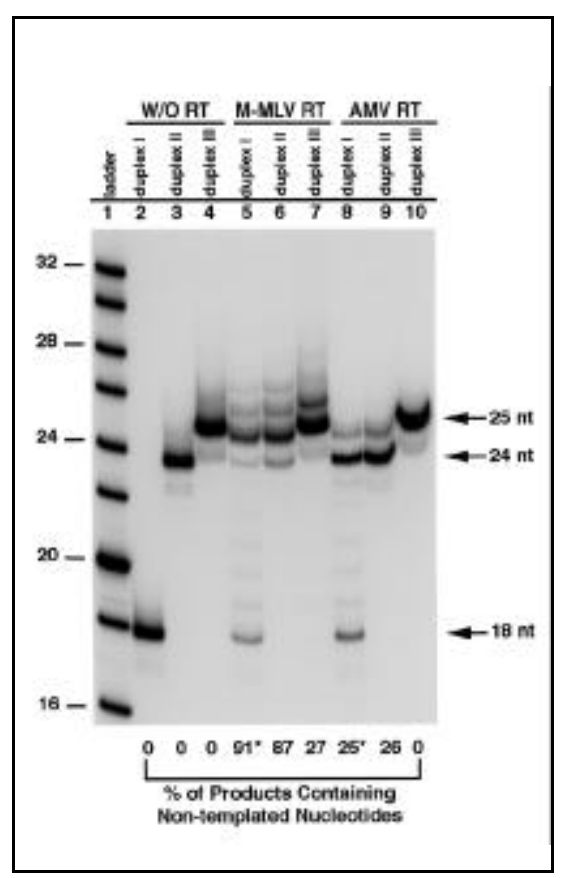

Figure 4. Effect of terminal structure on addition of nontemplated nucleotides. DNA/RNA duplexes I (5'-RNA overhang), II (blunt-end), and III ( $3^{\prime}$-DNA overhang) were incubated with all four dNTPs in the absence of reverse transcriptase (lanes 2-4), or in the presence of $200 \mathrm{U}$ MMLV reverse transcriptase (lanes 4-7) or $5 \mathrm{U}$ AMV reverse transcriptase (lanes 8-10). Oligonucleotides from the mixtures were analyzed by electrophoresis and autoradiography and quantified by phosphorimaging. Values were calculated by dividing the level of products containing greater than or equal to one nontemplated nucleotides by the total level of products that were greater than or equal to 24 nucleotides (duplex I and II) or greater than 25 nucleotides (duplex III) and multiplying by 100 . Asterisks indicate that the total level of products exclude 18-mer unextended products. 
transcriptase concentration affects the frequency of the addition of nontem plated nucleotides and that the level of TdT-like activity is lower at lower reverse transcriptase concentrations.

Reverse transcription is routinely performed at elevated temperature $\left(45^{\circ} \mathrm{C}-50^{\circ} \mathrm{C}\right)$ to reduce the impact of RNA secondary structure on cDNA synthesis. To examine the effect of tem perature on the TdT-like activity of reverse transcriptase, DNA/RNA duplex I (5'-RNA overhang) was incubated with MMLV and AMV reverse tran-

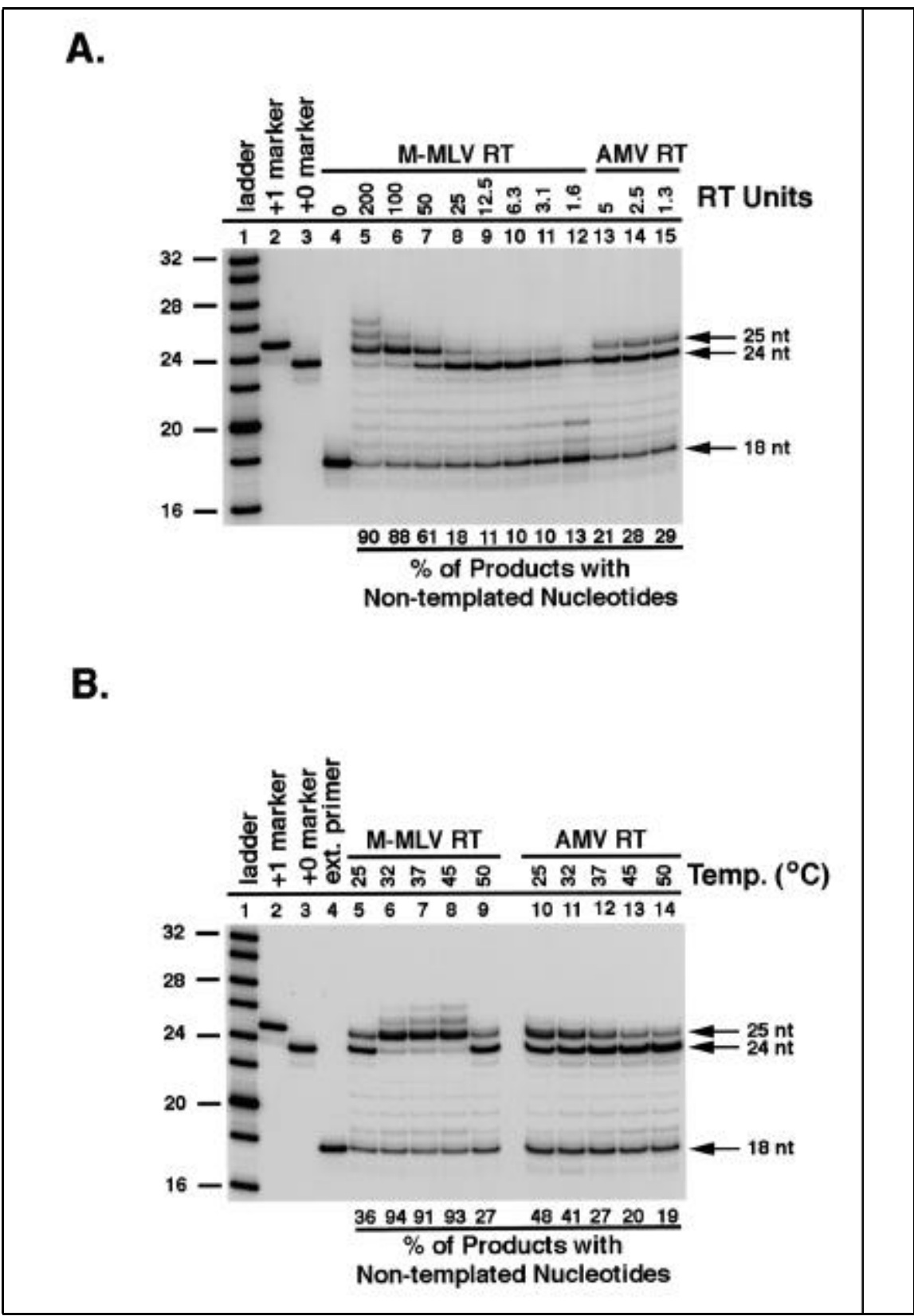

Figure 5. Impact of reverse transcriptase concentration and reaction temperature on the addition of nontemplated nucleotides. (A) DNA/RNA duplex I (5'-RNA overhang) was incubated with the indicated units of MMLV or AMV reverse transcriptase and all four dNTPs for $1 \mathrm{~h}$ at $45^{\circ} \mathrm{C}$ (A) or with $20 \mathrm{U}$ MMLV or $5 \mathrm{U}$ AMV reverse transcriptase and all four dNTPs for $1 \mathrm{~h}$ at the indicated temperatures (B). The oligonucleotides from the mixtures were analyzed by electrophoresis and autoradiography and quantified by phosphorimaging. Values were obtained by dividing the level of the primer extension products containing nontemplated nucleotides ( $>24$ nucleotides) by the total extension products $(\geq 24$ nucleotides) and multiplying by 100 . End-labeled oligonucleotide size marker (lane 1), oligonucleotide I (18 nucleotides, panel B, lane 4), II (24 nucleotides, lane 3), and III (25 nucleotides, lane 2).

scriptases at $25^{\circ} \mathrm{C}-50^{\circ} \mathrm{C}$. The results showed that temperature was not a significant factor in the template-dependent elongation (i.e., cDNA synthesis) of the 18-nucleotide oligonucleotide primer of the duplex (Figure 5B, lanes 5-14). However, the addition of nontemplated nucleotides was affected by temperature. At $25^{\circ} \mathrm{C}$, approximately $36 \%$ and $48 \%$ of the extended oligonucleotides generated by MMLV and AMV reverse transcriptase, respectively, contained nontemplated nucleotides (lanes 5 and 10 ). At $32^{\circ} \mathrm{C}-45^{\circ} \mathrm{C}$, the level of extended oligonucleotides with nontemplated nucleotides increased to $90 \%$ in assays containing MMLV reverse transcriptase (lanes 6-8). Unlike the results with MMLV reverse transcriptase, the level of extended oligonucleotides with nontemplated nucleotides decreased to $20 \%$ in assays containing AMV reverse transcriptase at $32^{\circ} \mathrm{C}-45^{\circ} \mathrm{C}$ (lanes $11-13$ ). At the highest temperature $\left(50^{\circ} \mathrm{C}\right)$, nontem plated nucleotides were present on only approximately $27 \%$ and $19 \%$ of the extended products recovered from assays containing MMLV and AMV reverse transcriptase, respectively (lanes 9 and 14). Therefore, although functioning over a wide range of temperatures, the TdT-like activity of reverse transcriptase is influenced by temperature and is reduced at $50^{\circ} \mathrm{C}$.

\section{DISCUSSION}

This study was prompted by our initial observation that the majority of clones generated by the $5^{\prime}$-RACE procedure contained extra nucleotides upstream of the $5^{\prime}$ end of the rotavirus gene 8-specific sequence. By analyzing DNA/RNA duplexes with defined terminal sequences, we have demonstrated that reverse transcriptase can add one, and less commonly two or three, nucleotides in a template-independent manner to the $3^{\prime}$ end of cDNAs upon the completion of template-dependent synthesis. The TdT-like activity of reverse transcriptase is substrate specific, as it catalyzed the addition of nontemplated nucleotides to DNA/RNA and DNA/DNA duplexes, but not to ssDNA or ssRNA. In comparison to DNA/RNA duplexes with blunt-ends, the TdT-like 
activity added nucleotides to duplexes with 3'-DNA overhangs much less efficiently. While any of the four dNTPs were used as substrates, dATP was the preferred substrate for TdT-like activity. Reverse transcriptase added nontemplated nucleotides to cDNAs at all enzyme concentrations examined, but only at high concentrations of reverse transcriptase $(\geq 100 \mathrm{U})$ was the addition of more than one nontemplated nucleotide to $\mathrm{cD}$ NAs readily detected. The TdT-like activity of reverse transcriptase functioned over a wide range of temperatures $\left(25^{\circ} \mathrm{C}-50^{\circ} \mathrm{C}\right)$ but exhibited peak activity at temperatures that are typically used in generating cDNAs by RACE and primer extension $\left(32^{\circ} \mathrm{C}-45^{\circ} \mathrm{C}\right)$.

$5^{\prime}$-RACE and primer extension have been widely used to determine the precise terminal sequences of cellular and viral RNAs. Under typical reaction conditions, MMLV reverse transcriptase can add nontemplated nucleotides to $70 \%-80 \%$ of $5^{\prime}$-RACE clones (Figure 1) and to greater than $90 \%$ of primer extension products (Figure 4), while AMV reverse transcriptase adds nontemplated nucleotides to $40 \%$ of $5^{\prime}$ RACE clones (data not shown) and to $25 \%$ of primer extension products (Figure 4). These findings raise concerns about the strict reliance of using these methods to determine the terminal sequences of RNAs. For cellular RNA, the presence of nontemplated nucleotides may be readily identified by comparing the terminal sequence of the cDNA to the genomic DNA sequence from which the RNA was derived. However, this approach is not applicable for cDNAs of RNA viruses because of the lack of a genomic DNA sequence to make a sequence comparison. Indeed, when using 5'-RACE or primer extension to determine the terminal sequences of RNAs of RNA viruses, it may be necessary to confirm its accuracy by an alternative method such as direct RNA sequencing.

Despite significant effort, we could not find assay conditions under which the TdT-like activity of reverse transcriptase was abolished. However, our analysis indicates that it is possible to reduce the incidence of the addition of nontemplated nucleotides in 5'-RACE and primer extension by using less reverse transcriptase, by raising the reaction temperature, or by a combination of both. Since the addition of nontemplated nucleotides cannot be completely eliminated, 5'-RACE clones can be expected to exhibit some degree of sequence heterogeneity at the junction of cDNAs and homopolymer tail. To avoid misinterpreting the sequence information gained from 5'-RACE clones, we recommend that at least two different dNTPs should be used in homopolymer tailing and that several cDNA clones should be independently prepared and their sequences comparatively analyzed.

\section{REFERENCES}

1.Both, G.W., A.R. Bellamy, J.E. Street, and J.L. Siegman. 1982. A general strategy for cloning double-stranded RNA: nucleotide sequence of the simian- 11 rotavirus gene $8 . \mathrm{Nu}-$ cleic Acids Res. 22:7075-7088.

2.Chen, D., C.Q-Y. Zeng, M.J. Wentz, M. Gorziglia, M.K. Estes, and R.F. Ramig. 1994. Template-dependent, in vitro replication of rotavirus RNA. J. Virol. 68:7030-7039

3.Clark, J.M. 1988. Novel non-templated nucleotide addition reactions catalyzed by pro- caryotic and eucaryotic DNA polymerases. Nucleic Acids Res. 16:9677-9686.

4.Estes, M.K. 1996. Rotaviruses and their replication, p.731-776. In B.N. Fields et al. (Eds.), Fundamental Virology. Lippincott-Raven Press, Philadelphia.

5.Frohman, M.A. 1990. RACE: rapid amplification of cDNA ends, p. 28-38. In M.A. Innis et al. (Eds.), PCR Protocols. Academic Press, San Diego, CA.

6.Frohman, M.A. 1993. Rapid amplification of complementary DNA ends for generation of full-length complementary DNAs: thermal RACE. Methods Enzymol. 218:340-356.

7.Frohman, M.A., M.K. Dush, and G.R. Martin. 1988. Rapid production of full-length $\mathrm{cD}$ NAs from rare transcripts: amplification using a single gene-specific oligonucleotide primer. Proc. Natl. Acad. Sci. USA 85:8998-9002.

8.Graves, B.J., S.P. Eisenberg, and S.L. McKnight. 1985. Alternate utilization of two regulatory domains within the Moloney murine sarcoma virus long terminal repeat. Mol. Cell Biol. 5:1959-1968.

9.McKnight, S.L. and R. Kingsbury. 1982. Transcription control signals of a eukaryotic protein-encoding gene. Science 217:316-324

10.Paliska, J.A. and S.J. Bendovic. 1992. Mechanism of DNA strand transfer reactions catalyzed by HIV-1 reverse transcriptase. Science 258:1112-1118.

11.Patel, P.H. and B.D. Preston. 1994. Marked infidelity of human immunodeficiency virus type 1 reverse transcriptase at RNA and DNA template ends. Proc. Natl. Acad. Sci. USA 91:549-553.

12.Patton, J.T., L. Salter-Cid, A. Kalbach, E.A. Mansell, and M. Kattoura. 1993. Nucleotide and amino acid sequence analysis of the rotavirus non-structural RNA-binding protein NS35. Virology 192:438-446.

13.Patton, J.T., M. Wentz, J. Xiaobo, and R.F. Ramig. 1996. Cis-acting signals that promote genome replication in rotavirus mRNA. J. Virol. 70:3961-3971.

14.Sambrook, J., E.F. Fritsch, and T. Maniatis. 1989. Electrophoresis of RNA through gels containing formaldehyde, p. 7.43-7.45. In J. Sambrook et al. (Eds.), Molecular Cloning. CSH Laboratory Press, Cold Spring Harbor, NY.

15.Swanstrom, R., H.E. Varmus, and J.M. Bishop. 1981. The terminal redundancy of the retrovirus genome facilitates chain elongation by reverse transcriptase. J. Biol. Chem. 256:1115-1121.

Received 19 June 2000; accepted 31 August 2000.

\author{
Address correspondence to: \\ Dr. John T. Patton \\ Laboratory of Infectious Diseases \\ National Institutes of Allergy and Infectious \\ Diseases \\ National Institutes of Health \\ 7 Center Drive, MSC 0720, Room 117 \\ Bethesda, MD 20892, USA. \\ e-mail: jpatton@niaid.nih.gov
}

